\title{
A magical history tour
}

\section{Take a trip to the end of the ice age with a fictional guide.}

\section{After the Ice: A Global Human History 20,000-5000 BC \\ by Steven Mithen \\ Weidenfeld \& Nicolson: 2003. 622 pp. $£ 25$}

\section{Robert L. Bettinger}

When the Pleistocene epoch gave way to the Holocene some 12,000 years ago, there was profound and rapid environmental and cultural change: the climate warmed, immense glaciers melted, rising oceans flooded ancient coasts, and an ice-age bestiary of lions, tigers, and elephants vanished. Humans around the globe were quick to exploit the opportunities created by this natural tumult and the vastly more productive environment that emerged in its wake. They developed new technologies. Some discovered and settled new continents. Others domesticated the plants and animals that feed the world today, and some of these gathered into the settled agricultural and trading communities from which the first civilizations rose.

After the Ice tells the story of these transformations. Its narrator is Steven Mithen, a well-published archaeologist who is perhaps best known for The Prehistory of the Mind (Thames \& Hudson, 1996), a book about the evolution of human cognition. Mithen has been equally active in the field, having excavated in Scotland, and currently in southern Jordan, to shed light on the transitions that are the subject of this book. His theoretical expertise and substantial field experience are evident in the even-handed and thoughtful treatment he gives to the evidence and interpretations of the many other scientists upon whom he must rely in telling this story.

In writing After the Ice, Mithen set out to make prehistory more accessible to the public, but the book's scope and detail will appeal mainly to those willing to invest some time and effort in learning about this subject. There are 52 relatively short chapters, most dealing with a site or series of related sites. The chapters are collected into sections that develop a coherent picture of the Pleistocene-Holocene transition in six large geographical areas: western Asia, Europe, the Americas, greater Australia and eastern Asia, southern Asia, and Africa.

Mithen presents the archaeological and palaeoclimatic evidence in plain English, without jargon, attending to details that help the reader understand the sites, the scientists who excavated them, what they found, and the natural and cultural processes that they illuminate. The text is quite comprehensible on its own, and extensive chapter notes at the end of book provide background, explana-

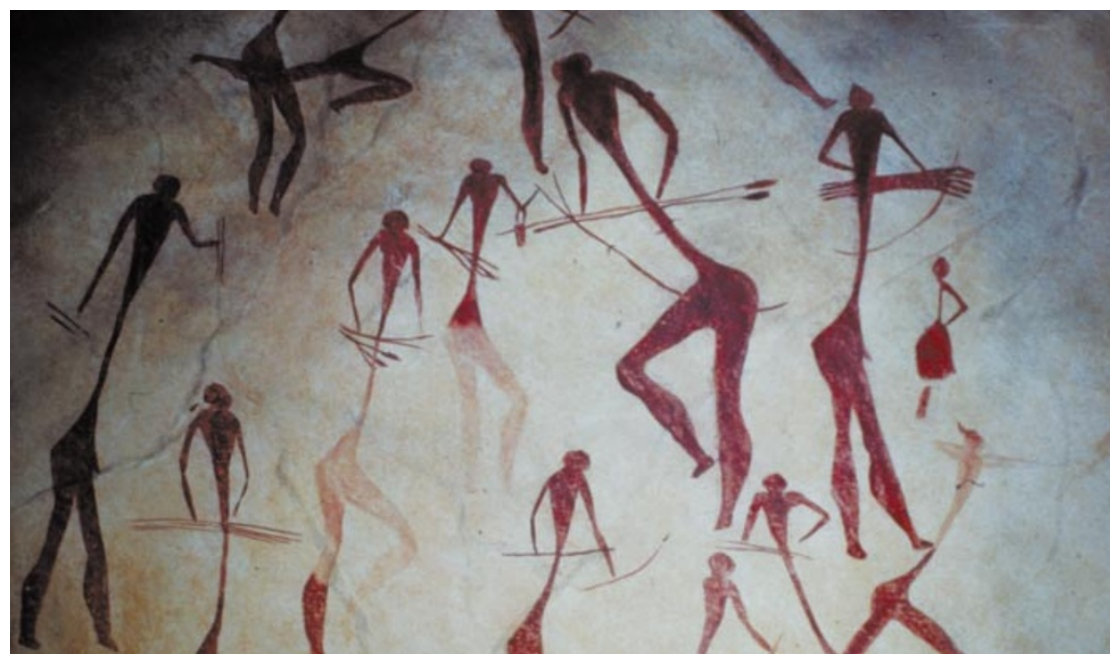

Time's arrows: these 6,000-year-old cave paintings from Spain depict scenes of hunting with weapons.

tory comment and citations of original references for the serious reader. Mithen presents and evaluates all of this evidence clearly, but what distinguishes this book is the way he tries to bring it to life for the lay reader.

He creates a fictional character, John Lubbock, who has the power to travel back through time to visit the sites described by Mithen and to participate, unseen, in the daily activities of their inhabitants. Lubbock experiences what Mithen imagines it would have been like to be alive at all of these places in the past. John Lubbock is based on the Victorian archaeologist and biologist of the same name, author of Pre-Historic Times, as Illustrated by Ancient Remains, and the Manners and Customs of Modern Savages (1865), a copy of which the fictional Lubbock carries and consults during his travels.

The disparity between the people that the fictional Lubbock meets and the depraved hunter-gatherers depicted in Pre-Historic Times is the device through which Mithen seeks to correct the popular stereotype that ignorance and superstition sentenced prehistoric hunter-gatherers to a subhuman existence of drudgery and want. In keeping with the modern anthropological view, the fictional Lubbock encounters people who are largely like ourselves, only more knowledgeable about their natural surroundings and more constrained by their technology. They are intelligent, yet fearful of the unknown; industrious, yet devoted to art, story-telling and long bouts of leisure; mostly well fed, but acquainted with malnutrition and disease; and caring with family and friends, yet capable of occasional violence.

It gets a bit crowded at times, with Mithen, two Lubbocks and an ever-changing retinue of native peoples and scientists. On the whole, however, the story is easy to follow, and although Mithen's imaginative reconstructions will give many archaeologists pause, they will probably help non-archaeologists to visualize the richness of prehistoric life.

Covering so many sites and such a broad timeframe, After the Ice is always on the verge of becoming an essentially descriptive account. Mithen avoids this by focusing on the key questions that continue to provoke debate about the Pleistocene-Holocene transition. What caused the extinction of Pleistocene megafauna - climate change or human overkill? Did humans enter the New World before 20,000 BC? Why did agriculture develop in the Holocene but not earlier? In general, Mithen's answers are solidly mainstream and reflect a careful weighing of the full range of evidence and arguments that will benefit non-specialists.

What Mithen can't seem to answer, even to his own satisfaction, is whether humans are better off as the result of the cultural developments he describes and those that followed, a question he takes up in the epilogue. He would not like to live in the past as a hunter-gatherer, but questions the worth of modern conveniences bought at the price of global pollution and environmental destruction - a trade-off that he fears will worsen in the future. This part rankles, not because the issues are trivial but because archaeology provides no answers. It is enough that archaeology can tell us about the past and sharpen our understanding of what it means to be human. After The Ice does both. Robert L. Bettinger is in the Department of Anthropology, University of California, Davis, California 95616, USA. 